\title{
The Usage Of New Media In Cultural Diplomacy: A Case Of Turkey
}

\author{
Berna Berkman Köselerli
}

\begin{abstract}
This study attempts to reveal new media usage in cultural diplomacy which is acting by Turkey. The interactions between governments in culture, art, education, science to improve relations are defined as cultural diplomacy. New media could be an important sphere to consolidate relations and dialogue between states in diplomatic affairs. Cultural diplomacy is also acted as a soft power tool to control and effect public perceptions. The function of new media in cultural diplomacy is considered with a quantitative research by applying a case study in this study. The official Twitter accounts of Foreign Ministry of Turkey are examined in a month period in terms of their content. It is seen that there is a more need to lessen disagreements, to change the misperception about publics, to repair governmental relations by acting cultural diplomacy in Turkey. The governmental organizations should add new communication channels like new media to get feedback of different voices, values, opinions. If communication means are used to support exchanging information and culture, thus the gap between publics may diminish. Diplomatic facilities, events or activities could be reported to the publics instantly by using new media.
\end{abstract}

Keywords: Cultural Diplomacy, Soft Power, Turkey, New Media

\section{Introduction \\ Conceptual Framework}

Cultural diplomacy, in the strict sense, is a governmental practice that operates in the name of a clearly defined ethos of national or local representation, in a space where nationalism and internationalism merge. Cultural diplomacy can also be practiced by other agencies such as non-state actors and various initiatives of civil society. So the meaning of cultural diplomacy has broadened considerably, thus the term has come to be used as a partial or total replacement for many previously used notions, such as foreign cultural relations, international cultural relations, international cultural exchange or international cultural cooperation (Ang, I. et al., 2015: 367). On the other hand, the well-known definition of M. Cummings (2009: 1) points out that the cultural diplomacy refers to the exchange of ideas, information, art and other aspects of culture among nations and their peoples in order to foster mutual understanding.

The cultural diplomacy approaches are gathered in three basic heading by the report of Cultural Diplomacy Platform which was established by the European Union Commission in 2016. 'The public diplomacy approach', according to which the government has a monopoly on the practice and goals of cultural diplomacy; 'the strategic communications approach', which does not necessarily entail the involvement of the government but implies its role in fostering a specific strategic interest, and 'the cultural relations approach', which looks at cultural diplomacy as a practice based on dialogue and collaboration, detached from a soft power (2016: 2). According to the report, states are still perceived as the main actors carrying out cultural diplomacy, new stakeholders become more active such as non-governmental organizations, private entities, civil initiatives and etc. besides the state's monopoly.

Cultural diplomacy is considered as a part of public diplomacy, advocated as a more citizen-oriented form of diplomacy than the standard model, whose targets are no longer other governments so much as diverse national and global audiences and publics (Ang, I. et al., 2015: 368). Cultural diplomacy constitute a practical agenda for integrating the work of cultural institutions into the existing structures and working practices of public diplomacy (Bound, K. et al., 2007: 65). Where the rise of public diplomacy could be described as the shift from few-to-few communication to few-to-many, this era will be characterized by the growth of many to many interactions (Bound, K. et al., 2007: 75). Cultural diplomacy is differently implemented from traditional diplomacy; official visitings and statements. Public opinion, values, needs and demands become important in diplomacy issues. According to K. Bound et al. (2007: 68- 70) social software platforms help to 
coordinate the growing numbers of cultural players, and cultural institutions should continue to develop online services for their visitors.

The concept of cultural diplomacy, in some arguments, can be seen as activities for shaping opinions about the country's cultural heritage or promoting the country with the aid of history itself. As Ryniejska Kieldanowicz (2009: 2) countries recognize that showing cultural heritage provides them with an opportunity of presenting who they are, creating positive images, thus helping to achieve their political aims. Ryniejska (2009: 10) stresses that cultural diplomacy is commonly accepted as brand management and identity building. Both are based on the task of creating a proposition or undertaking, usually based on values, that should be effective to impact in many situations and many target groups.

Cultural diplomacy is often viewed negatively due to its connotations with colonialism, imperialism and propaganda. Dominant states have always used culture to transmit political, social, cultural and economic values (Nisbett, 2013: 558). The term discussed differently by M. Nisbett who claims that cultural diplomacy could be a positive diplomatic action and international cultural relations if it is not used for serving propaganda.

Zamorano (2016: 180) considers cultural diplomacy as an area of government intervention and based on various temporal, communicative and political participation variables, and he put forwards its boundaries in relation to other activities such as public diplomacy and propaganda. In this point of view, cultural diplomacy is associated with a variety of goals that result from contextualized definitions of national interest and securing power. By this reason, the borders between this group activities and public diplomacy, branding and propaganda is blurring (2016: 181). Cultural diplomacy is structured following diverse government strategies of bureaucratic, social or industrial pre-eminence and the power relations of these spheres in different contexts. According to Zamorano's approach, the historical developments in diplomacy displays that war and geopolitical tensions often result in cultural diplomacy serving as neo-propaganda (2016: 181). Zamorano (2016: 175-176) mentions that cultural diplomacy is integrated with soft power arguments and employed separately from hard power, so it can be use as a soft power tool to constitute the persuasion mechanisms without using coercive methods.

S. Mark (2009: 1) points out cultural diplomacy as its contribution to cultural relations and domestic objectives. According to Mark, cultural diplomacy has the potential to become a much more powerful tool for improving a country's image, nation branding, social cohesion. In the point of Mark's view, cultural diplomacy is defined as the deployment of state's culture in support of its foreign policy goals or diplomacy (2009: 7). Cultural diplomacy's functional objectives also include advancing trade, political, diplomatic and economic interests, developing bilateral relationships across the board, including economic, trade, political, cultural and diplomatic elements, connecting with groups abroad that are important to the cultural diplomacy practitioner (such as diasporas), and helping to maintain bilateral relationships in times of tension (2009: 9).

New media give some operational advantages to policy makers on managing information networks. As Hwajung Kim (2011: 2) says, the new way of communication with information technologies provides new opportunity for cultural policy makers to broaden their target audience and to promote culture even more widely with its new media platforms. Cultural diplomacy using information technologies can strengthen soft power if cultural policy makers make use of new communication technologies effectively and strategically. H. Kim (2011: 1) defines cultural diplomacy as forming international bridges and interactions, identifying networks and power domains within cultures and transcending national and cultural boundaries. It is important in Kim's approach that implementing cultural exchanges and developing communication through information technologies bringing nations people closer together (2011: 12). The changes on political-economic system, neoliberal policies, globalization, the participation of new diplomatic actors such as nongovernmental organizations, private entities, civil initiatives transform the way of cultural diplomacy. The emerging technologies and the digital networks are accompanying to this recently changes and can use so as to support the international cultural relations.

\section{Historical Development of Cultural Diplomacy}

In the view of Espinosa (1976: 35-36), the practice of cultural diplomacy is rooted to the 19 th century especially in the continent of America. In the early 19 th century, North Americans came in closer contact with South American countries. From the mid 19 th century there was a noticeable awakening of interest between in all South American colonies, and the beginning of more lasting cooperative activities in the sciences, archeology, ethnology, education, history and literature.

Similar initiative actions have been occurred in Europe, nearly in the same historical period. Paschalidis, (2009: 277-279) who categorizes the development of interconnected cultural relations in historical phases, emphasizes that the emergence 
of foreign cultural affairs dates back to 1870s in Europe along with the beginnings of Cultural Institutes abroad. The establishment of such national associations coincide with the age of neo-imperialism. The origins of the globally familiar presence of the British Council, the French, the Italian or the Goethe Institute, lie in the mission imperialism of European colonialism.

As Paschalidis (2009: 280-281), the institutionalization of external cultural policy widened with the I. World War. The Cultural Institutes along with the various related bodies and activities (scholarships, student and academic exchanges, art exhibitions, theatre, concert tours, etc.) become standard feature of the official external cultural policy of great countries. States initiated, administered and financed these cultural policies, but it was seen that the ideal of cultural nationalism had replaced by the cultural propaganda.

As Glade's (2009: 240-241) expression, cultural diplomacy began as a permanent function at the State Department in the 1930s. However this diplomatic affair became increasingly important in the 1940s and 1960s along with public diplomacy. Cultural diplomacy was in progress with new actors like US Information Agency and UNESCO after the II. World War. Paschalidis (2009: 282) mentions that despite the efforts of UNESCO on international cultural cooperation, culture was politicized and turned into a vehicle for ideology among the East and West Blocs.

Glade (2009: 242) states that culture was enlisted in the service of diplomacy within cooperation; when the II World War ended and once a new set of challenges came into view, organizational mechanisms were implemented for political, social, cultural renovation and economic reconstruction of Western Europe. In accordance with this effort, UNESCO (1946), an affiliated agency of UN, was established as a forum for cultural diplomacy (Glade, 2009: 243). On the other hand, US Information Agency was established in 1953 for monitoring public policies abroad and presenting government policies. The Voice of America, which had been launched in 1942 for multilingual broadcasting, were either modified and transferred to the Department of State for a sustained program in public, as well as, cultural diplomacy and the Marshall Plan (1948), which was a financial support program, was acted as an supplementary element in European reconstruction effort (Glade, 2009: 242-243).

Until the end of Cold War, Great Britain, France, Germany, USA and Soviet Union were the pioneer forces in terms of creating the instruments to the external cultural policy. Since then, 'soft power' come to forefront and various instruments have been developed by a range of other countries to promote their diplomatic agendas (Paschalidis, 2009: 283). The political-economics landscape evaluated into multipolar system after the Cold War. There is a need to promote mutual understanding and reciprocal dialogue by bridging cultural relations in the new era of diplomacy which is conducting with multi-actors and new communicative tools.

\section{A Discussion on the Cultural Diplomacy of Turkey}

\subsection{Actors}

Foreign Ministry of Turkey constitute a department on cultural diplomacy in 2010 to keep close relations with foreign countries and coordinate the operation of the public foundations (YEE) and official entities (TIKA, AFAD, YTB) which are serving for international social and cultural activities. Multilateral platforms (UNESCO), bilateral agreements, scholarships, mutual cultural days/ years, international exhibitions and fairs are also supported by the Foreign Ministry within the scope of cultural diplomacy. Essentially, the institutionalization of cultural diplomacy in Turkey dates back to older times. In this context, Turkish Cooperation and Coordination Agency (TIKA) was established in 1992 as a technical aid organization under the Ministry of Foreign Affairs to provide the adaptation and the developmental needs of the Turkic Republics after the disintegration of the Soviet Union. ${ }^{1}$ Since 2002, TIKA has expanded its function through the development assistance activities which are conducted abroad and become a global organization as a new policy aspect of Turkish Prime Ministry. Its projects are undertaken by more than 50 Program Coordination Offices and also in 150 countries ranging from Central Asia and the Balkans to the Middle East, Africa, Latin America and the Pacific Islands and operate without discriminating race, language, religion and sect. ${ }^{2}$ Another governmental agency, Disaster and Emergency Management Presidency (AFAD), acting in accordance with Prime Ministry, supports humanitarian assistance to over 50 countries around the globe

\footnotetext{
1 http://www.tika.gov.tr/en

2 Turkish Cooperation and Coordination Agency (2014), Annual Report, Retrieved at September 04, 2017, from http://www.tika.gov.tr/upload/2016/INGILIZCE\%20SITE\%20ESERLER/FAAL\%C4\%BOYET\%20RAPORLARI/PDFLER/FR2014_ENG.pdf
} 
at the international level. The agency is providing various facilities to refugee camps like housing, healthcare, education, psychological support. 1

The Foreign Ministry established a new agency in 2010 to strengthen the social and cultural relationships with related countries. Presidency for Turks Abroad and Related Communities (YTB) is engaged in coordinating Turkish citizens and related communities abroad, and students studying in Turkey with international scholarship. YTB try to announce its activities in social media platforms (Facebook, Twitter, YouTube channel) and has an online library in its web sites ${ }^{2}$ The field of cultural diplomacy is expanded by the participation of new actors in Turkey. As a public foundation, Yunus Emre Institute (YEE) started to operate in 2009 to promote Turkish language, its history, culture and arts, and create informational documents on cultural issues, build the bridges between Turkey and other countries by intercultural exchange. Several activities are organized to represent Turkish culture with the international events. The organizations are represented in its web site and the page has an open access to various social media platforms of the Institute (Twitter, Facebook, Instagram, YouTube channel, Google+). A national Voice Radio is on air via the web site of the Institute which is sharing Turkish music to the foreign and domestic publics. ${ }^{3}$

The Foreign Ministry is sometimes operating along with the Ministry of Culture and Tourism while carrying out international cultural facilities. Directorate General of Libraries and Publications of this Ministry has a project for funding authors by supplying their translation and publication cost. While Directorate General of Fine Arts is arranging international art exhibitions, Directorate General of Promotion supports the student exchange programs, and all these actions are driven under the Ministry mentioned above. On the other hand, a web site, with a campaign concept 'Turkey Home', is constructed to make a contribution of Turkey's global outlook and the related social media platforms are attached to the campaign page. ${ }^{4}$ It has reached 6 million users on social media platforms (Twitter, Facebook, Instagram, Linkedln, Vine, Google+). The Ministry of Culture and Tourism also established a Cultural Diplomacy Bureau in 2014 and begin to act intercultural projects, for instance giving travelling awards to the foreign students. Because of the new establishment of the Bureau, social media usage is limited to input information about Turkey's culture in digital platforms.

The constitutions on higher education in Turkey make an implicit and indirect contribution to the cultural diplomacy, even tough having different missions. For instance, The Higher Education Council (YOK) is funding student and academic exchange programs as the name of Erasmus, Farabi, Mevlana and prepared a web site with a topic 'Study in Turkey' to announce the acting program currently. ${ }^{5}$ In addition, UNESCO Chair in Cultural Diplomacy, Governance and Education is founded at Istanbul Aydın University in 2015. The constitution aims to build an international network and bridge by executing the exchange of opinions, values, traditions, and other aspects of culture and identity. The international peace and sustainability is the another issue of the Chair, in this regard international meetings, conferences are organized and periodicals are published. Briefly, the cultural diplomacy actors are operating in a decentralized manner in Turkey's landscape, but the several cultural activities are supported for consolidating close relations.

\subsection{Tools}

The function of new media in cultural diplomacy is considered with a quantitative research by applying a case of Turkey in this study. Twitter accounts of Foreign Ministry of Turkey are examined by using an empirical analysis. The Ministry arranged official Twitter accounts in four language (Turkish, English, French, Arabic) in 2009. The official Twitter accounts (@TC_Disisleri, @MFATurkey, @MFATurkeyFre, @MFATurkeyAra) of Foreign Ministry are followed in a month period, from 1 th August to 1 th September, in terms of their contents. The analysis of 222 tweets are considered also with a relevant evaluation including the role of new media in cultural diplomacy.

Total amount of Twitter messages which are posted to the page (@TC_Disisleri) within the research period are 88, and 58 of them are retweet. Tweets are concern with official statements of the Turkish Ministry on the regional and global developments. Retweets are belongs to the official Twitter account of Foreign Minister to present the foreign visitings and meetings. Besides, the page is also examined with its attached items such as link, photograph, video, hashtag (\#), mention

\footnotetext{
${ }^{1} \mathrm{https}: / / \mathrm{www}$. afad.gov.tr/en/

2 https://www.ytb.gov.tr/

${ }^{3} \mathrm{http}: / / w w w . y e e . o r g . t r / e n /$

${ }^{4} \mathrm{http}: / /$ www.hometurkey.com/

${ }^{5}$ http://www.studyinturkey.gov.tr/
} 
(@). In a monthly period, this Twitter account includes 27 link in which of them related with official news cooperations (Anadolu Agency, TRT Channel). The account reports routinely official statements and opinions of Ministry by the links. As a commonly used way, photographs are uploaded to present formal agenda of Foreign Minister. The page account is including 55 photograph, but video sharing is not used as an attachment tool. Hashtag and mention items are displaying the mutual interactivity in Twitter platforms. The number of hashtags are 74 in the page. While the hashtags was posted frequently, the mentions take place rarely in the page. Hashtags are giving references to the countries (\#Turkey, \#Russia, \#lraq) and also the important days and events. The official accounts (@MFATurkeyFre, @MFATurkeyAra) which are reporting the messages in French (23 tweet) and Arabic (20 tweet) languages are less activated. In these accounts, all tweets are shared only with a link attachment to the Ministry web site. Besides, the pages don't include any hashtag or mention. The account of '@MFATurkey' is commonly used with interactive items such as mentions and hashtags. The tweets (20) and retweets (57) are related with foreign contacts and official statements (See the Table 1).

\begin{tabular}{|l|l|l|l|l|l|l|l|}
\hline \multicolumn{2}{|l|}{ Table 1. Official Twitter Account of Foreign Ministry of Turkey } \\
\hline & Tweet & Re-tweet & Link & $\begin{array}{l}\text { Photo } \\
\text { Image }\end{array}$ & Video & $\#$ & $@$ \\
\hline @TC_Disisleri & 30 & 58 & 27 & 55 & - & 74 & 1 \\
\hline @MFATurkey & 34 & 57 & 24 & 65 & - & 93 & 15 \\
\hline @MFATurkeyFre & 23 & - & 23 & - & - & - & - \\
\hline @MFATurkeyAra & 20 & - & 20 & - & - & - & - \\
\hline
\end{tabular}

It is seen that activities on cultural diplomacy are not represented in these main Twitter Accounts of Foreign Ministry. Instead of this, cultural affairs are represented in another Twitter account, called as 'public diplomacy. The page is driven by the Public Diplomacy Coordination Office. The Office is operated under the organizational structure of Prime Ministry and opened access its Twitter account in 2011 in four languages. The page (@BasbakanlikKDK) is announcing the international cultural affairs of Turkey by retweeting the other pages related to TIKA, AFAD, YTB, YEE. The total amount of the Twitter messages are 25 in a month period and 24 of them are retweet. In the account, 10 links, 19 photographs, 2 videos, 17 hashtags, 4 mentions are sited. The page contents are including the announcement of student exchange programs, courses on Turkish language, seminars, scholarships, celebrating cultural days/ years and humanitarian aid organizations.

Consequently, the Ministry departments began to utilize new media tools in diplomacy, but so to say, the departments should benefit more robustly from interactive features and operational capacity of new media for informing and promoting the cultural diplomacy activities. The instant messages and interactive attachments are used limitedly, therefore the intercultural relations aren't so visible and the usage of new media remains its weakness. Cultural diplomacy is represented on new media platforms in a decentralized way and still evaluated as a subset of public diplomacy affairs. As it is understood, the usage of new communicative tools in cultural diplomacy is comprehended in a narrow scale by the officials.

The Foreign Ministry prefers to implement cultural diplomacy in practice with its real actors instead of virtual tools and methods.

\section{Conclusion}

The rise of new media platforms is enabling the users to access huge masses and transmit opinions, values and demands. Diplomatic facilities, events or activities can be reported to the foreign publics instantly by using new media platforms. New communication technologies has been rapidly emerging and growing especially in the advanced capitalist economies. Dominant states have more capacity to operate new media tools and its outputs. There is a need to change the misperception between publics, and to repair the governmental relations in a compromising manner by acting cultural diplomacy in Turkey. The Foreign Ministry of Turkey have a remarkable capacity to restructure cultural diplomacy, but the Ministry departments are lacking in raising new media platforms in some respects. The officials should prefer to act strategies for improving new communicative tools and platforms in diplomacy.

The digital networks on cultural diplomacy are required to coordinate the intercultural activities and keep close relations with publics. Governments should increase the coordination with new stakeholders of cultural diplomacy so as to better exchange. If a country try to impose its cultural heritage, values and products by one-sided, the diplomatic action will be 
turn into propaganda or cultural imperialism. But, if the countries establish mutual understanding, reciprocal dialogue, interconnectivity and multi-dimensional cultural relations, this could be repair and reconstruct the relations. The governmental organizations should add new communication channels like new media to reach publics to improve cultural relations. Furthermore, getting feedback of different voices, values, opinions by new media can remove prejudices against different identities. As Cunningham (2010: 113) says, "strategic communication can be built by utilizing new media accurately." If the communication means are used to support exchanging information and culture, thus the gap between publics may diminish.

\section{References}

[1] Ang, I., Isar, Y. R. and Mar, P., (2015) "Cultural Diplomacy: Beyond The National Interest?", International Journal of Cultural Policy, V. 21/ 4, 365-381.

[2] Bound, K., Briggs, R., Holden, J. and Jones, S. (2007), Cultural Diplomacy, London: IPrint.

[3] Cummings, M. C., (2009) "Cultural Diplomacy and The United States Government: A Survey", Cultural Diplomacy Research Series, (p. 1-15), http://www.americansforthearts.org/by-program/reports-anddata/legislation-policy/naappd/cultural-diplomacy-and-the-united-states-government-a-survey.

[4] Cunningham, T., (2010) Strategic Communication in the New Media Sphere, Joint Forces Quarterly, Issue 59, 4 th quarter, $110-114$.

[5] Espinosa, J. M., (1976) Inter-American Beginnings of US Cultural Diplomacy, 1936-1948, Washington: Department of State Publication, https://babel.hathitrust.org/cgi/pt?id=msu.31293011707795; view=1up;seq=54

[6] EUNIC, (2016), "Cultural Diplomacy As Discipline and Practice: Concepts, Training and Skills", Final Report of European Union National Institutes for Culture, (p. 1-52),

[7] Glade, William, (2009) "Issues in the Genesis and Organization of Cultural Diplomacy: A Brief Critical History", Journal of Arts Management, Law \& Society, V. 39/ 4, 240-259.

[8] http://www.culturaldiplomacy.org/pdf/casestudies/Hwajung_Kim_Cultural_Diplomacy_as_the_Means_of_Soft_ Power_in_the_Information_Age.pdf

[9] http://www.cultureinexternalrelations.eu/2017/01/20/cultural-diplomacy-as-discipline-and-practice-conceptstraining-and-skills/

[10] Kim, Hwajung, (2011) "Cultural Diplomacy as the Means of Soft Power in an Information Age", Institute For Cultural Diplomacy, (p. 1-18),

[11] Mark, S., (2009) "A Greater Role For Cultural Diplomacy", Netherlands Institute of International Relations Clingendael, (p. 1-44), https://www.researchgate.net/publication/242084249_A_Greater_Role_for_Cultural_Diplomacy

[12] Nisbett, M. (2013) "New Perspectives on Instrumentalism: An Empirical Study of Cultural Diplomacy", International Journal of Cultural Policy, V. 19/ 5, 557-575.

[13] Paschalidis, G., (2009) "Exporting National Culture: Histories of Cultural Institutions Abroad", International Journal of Cultural Policy, V. 15/ 3, 275-289.

[14] Ryniejska Kieldanowicz, M., (2009) "Cultural Diplomacy As a Form of International Communication", Institute for Public Relations Research, (p. 1-21), http://www.instituteforpr.org/wpcontent/uploads/Ryniejska_Kieldanowicz.pdf

[15] Zamorano, M. M., (2016) "Reframing Cultural Diplomacy: The Instrumentalization of Culture under the Soft Power Theory", Journal of Current Cultural Research, V. 8, 166-186. 